\title{
Delayed implantation combined with precocious sexual maturation in female offspring: a story of the stoat
}

\author{
S Amstislavsky¹, E Brusentsev ${ }^{1}$, E Kizilova ${ }^{1,2}$ \\ ${ }^{1}$ Institute of Cytology and Genetics/Russian Academy of Sciences, Russian Federation \\ ${ }^{2}$ Novosibirsk State University/Natural Sciences Dept, Russian Federation
}

Corresponding author e-mail: amstis@yandex.ru

\begin{abstract}
The objective of this study was to investigate the precocious sexual maturation in stoat females. We confirmed oestrus and successful mating in newborn stoats; and documented ovulation, preimplantation embryo development, embryonic diapause and implantation during first nine months of life. A total of 100 embryos at different stages of development were flushed from the oviducts and uterine horns obtained from female stoats (Mustela erminea) between day 26 and day 251 after birth. At same time points, the ovaries were fixed, sectioned and analysed for the presence of follicles and corpora lutea.

Newborn stoat females entered oestrus during the first month of their life, i.e. in MayJune in Northern hemisphere, and may stay in oestrus the whole summer until impregnated by an adult male. When mated, these females ovulated 3-4 days later. Embryos arrived in the uterus 11-12 days post coitum, slowly expanded and persisted as diapausing blastocysts until implantation 8-9 months later. We described the phenomenon of obligate delayed implantation in juvenile stoat females including timing of preimplantation embryo development and concluded that the stoat represents an unparalleled model for studying precocious sexual maturation and delayed implantation.
\end{abstract}

\section{Introduction}

Embryonic diapause is an evolutionary strategy to ensure that offspring are born when maternal and environmental conditions are optimal for survival [1]. Involvement of hormones, especially ovarian steroids, in diapause regulation is well known [1,2]. Molecular mechanisms underlying embryonic diapause have been thoroughly investigated in different mammalian species [2-8].

Currently, embryonic diapause has been found in 130 species of mammals belonging to a variety of zoological taxa [2,9]. Many of Carnivora species, members of Mustelidae, Mephitidae, Odobenidae, Otariidae, Phocidae, and Ursidae families, are characterised by embryonic diapause. Among eutherian mammals, Mustelidae family contains the greatest number of species that exhibit embryonic diapause $[2,10]$, this has stimulated studies of the evolutionary origin of delayed implantation in mustelids $[11,12]$. A particular interesting pattern of obligate diapause was described in the stoat and the long-tailed weasel, which express an unique combination of precocious sexual maturation of females and delayed implantation [14-16].

The stoat (Mustela erminea) is widespread in the palearctic zone of Eurasia and North America [15]. Being introduced in New Zealand, stoat adapted well to the new environment and nowadays is considered as a pest threatening the iconic New Zealand bird species [17]. Stoats are resistant to 
any form of domestication [10] and breeding stoats in captivity is challenging. Nevertheless, an experimental captive bred population of stoats was maintained in Novosibirsk for decades, allowing gain in knowledge of the reproductive physiology of this species $[10,15,16,19,20]$. It was observed that juvenile stoat females are able to mate successfully with adult males during the weaning period $[10,15,16]$. This shortening of reproductive life time was suggested to be one of the reasons of stoat's prosperity throughout its historical range, as well as in the areas of its introduction [18].

The stoat is characterised by a constellation of interesting reproductive mechanisms $[15,16,20]$. This article addresses the peculiarities of reproduction in this mustelid species and discuss the "a story of the stoat" combining our own experimental observations on the captive population in Novosibirsk with literature.

\section{Experimental design}

To study stoat's early embryonic development in vivo, a total of 100 embryos were flushed from reproductive ducts of 13 female stoats at the age of 26- to 92-days. For this purpose, each of female was paired with an adult male; mating was registered by visual observation of coitus and presence of spermatozoa in the vaginal smear. Oviductal and/or uterine flushings of females from first until the 270th day after their fertile mating were analysed. For this purpose, semi-castration (surgical excision of one ovary, oviduct and uterine horn) under anaesthesia was performed. Presence of spermatozoa, ovulated oocytes and/or embryos of different developmental stages in oviduct and/or uterine horn were registered by microscopic examination. Ovulated oocytes and embryos were photographed and some fixed for detailed microscopic study. In parallel, morphological changes in ovaries were monitored.

\section{Materials and Methods}

The experiments were carried out on the Research Station at Novosibirsk, Russia. This Mustelidae Research Station was founded by Dmitry and Julia Ternovsky in 1970. All animals were kept in individual wire mesh cages measuring $150 \times 150 \times 200 \mathrm{~cm}$ (length $\times$ width $\times$ height), and each cage included a nest box measuring $120 \times 35 \times 35 \mathrm{~cm}$. Throughout the year, the animals were exposed to the outdoor temperature and were given wet food prepared in a local kitchen and water ad libitum.

Newborn stoat females were monitored from postnatal day 10 onwards for signs of oestrus by vaginal smears and external inspection. Prooestrus was characterized by a steady increase of the vulva, reaching its maximum size during oestrus, when it changed it colour into reddish-pink [10]. Oestrus was confirmed by the presence in the vaginal smear comprising about 90 percent flattened cornified cells without nuclei [10]. After confirming oestrus by both methods, each animal was paired with an adult male of proven fertility. In all the cases, mating occurred soon after the pairing. To prove a fertile mating, a vaginal smear was taken and checked for the presence of spermatozoa using light microscopy (x 200).

Mated stoat females $(n=13)$ were objected to semi-castration (surgical excision of one ovary, oviduct and uterine horn) under anaesthesia (see below) at various times between the day of mating and prospective day of implantation nine months later. In addition, all animals were finally sacrificed to obtain the remaining ovary, oviduct and uterine horn post mortem at variable time points to cover the whole period of embryonic diapause. A total of 25 oviducts and uterine horns of 13 females (one uterine horn was not investigated) were checked for the presence of spermatozoa, oocytes and embryos. 
To induce anaesthesia, ketamine hydrochloride $(15.0 \mathrm{mg} / \mathrm{kg}$ body weight, i.m., Ketamine 50 $\mathrm{mg} / \mathrm{mL}$, Moskovskii Zavod Endokhrinnih Preparatov, Moscow, Russia) was used followed by 50 $\mathrm{mg} / \mathrm{kg}$ nembutal (i.m., Nembutal ${ }^{\circledR}$, Dainabot, Osaka, Japan). The hair coat was shaved at the linea alba, the skin washed and disinfected with iodine (Solutio iodi spiirituosa 5\%, Novosibirsk, Russia) and $70 \%$ alcohol. The females were placed on a clean thick towel on the operating table, the skin incised at the linea alba, the muscles and fat opened bluntly, and the peritoneum incised. The fat covering the ovary was lifted with forceps and the whole uterine horn exposed. Two sterile silk ligatures (3-0 Prolene, Ethicon, Hamburg, Germany) were placed at the proximal part of the uterine horn as close as possible to the bifurcation. Two more ligatures were positioned above the ovary to avoid bleeding after extirpation. Then the uterine horn was cut between the two ligatures, the ovary was cut off between the two ligatures, and the whole horn together with the ovary and oviduct was separated from the fascia with scissors. Ovaries were separated from the oviducts and fixed for histology. The oviducts were cut close to the uterotubal junction and were flushed $10 \mathrm{~mL}$ medium M199 (Vector, Novosibirsk, Russia) through a blunted needle in a petri dish. The uterine horns were also flushed with $20 \mathrm{~mL}$ of M199.

After removal of the semi-urogenital tract, the peritoneum and muscle layers were sutured with soluble material (3-0 catgut, B. Braun, Melsungen AG, Germany) and the skin with sterilized silk (3-0 Prolene, Ethicon, Hamburg, Germany). The skin was protected with antibiotic powder (Streptomicine, Kurgan, Russia) and aerosol wound spray (Septonex ${ }^{\circledR}$, Spofa Co., Prague, Czech). After surgery, the females were treated with antibiotics (Bicilline ${ }^{\circledR}-1$ s.c., Sintez, Russia) and observed in cages inside the house for the next 24 to $96 \mathrm{~h}$.

To obtain the remaining uterine horn, the animals were euthanised by cervical dislocation after being anaesthetised as described above. The second uterine horn together with the second oviduct and ovary were removed post mortem, ovaries were fixed and embryos were flushed as described above. If flushing the uterine horns was not possible and prominent uterine swellings were observed, the female was designated as being pregnant with implanted embryos.

The oviductal and uterine flushings were evaluated by light microscopy. Presence of spermatozoa, oocytes and embryos was documented (Table 1). The oocytes and embryos were briefly evaluated for the stage of development using MBS-10 stereomicroscope (St. Peterburg, Russia) (x70) and were further examined and pictured under Wild Leitz inverted microscope (Wetzlar, Germany) up to 300x magnification depending on their size. The stage of development was estimated. Phasecontrast microscopy, Nomarsky optics and DIC were used for the evaluation and photography.

The ovaries were fixed in Bouin's solution, and stored in a refrigerator at +4 으 $\mathrm{C}$ before further processing. During processing the ovaries were embedded in paraffin, sectioned at $8 \mu \mathrm{m}$ and stained with haematoxylin and eosin. Sections were analysed and photographed with a Wild Leitz microscope (Germany) and later with an Olympus AX 70/AX7 microscope with a fully automatic exposure photo tube (Olympus, U-CMAD-2, Japan) supplied with a soft imaging system analySyS (Soft Imaging System GmbH, Germany).

\section{Results}

On days 1 and 2 post coitum (pc) no ovulated oocytes, but actively moving spermatozoa were present in the reproductive ducts of the studied females. Large preovulatory follicles were present in the ovaries of such females (Figure $1 \mathrm{~A}$ ). Figure 2A illustrates oocytes aspirated from these follicles. At this stage, the oocytes were surrounded by numerous cumulus cells, representing the classic cumulus-oocyte complex. Fresh ovulation sites were seen in the ovaries of animals that had ovulated 72 - 96 hours pc. 


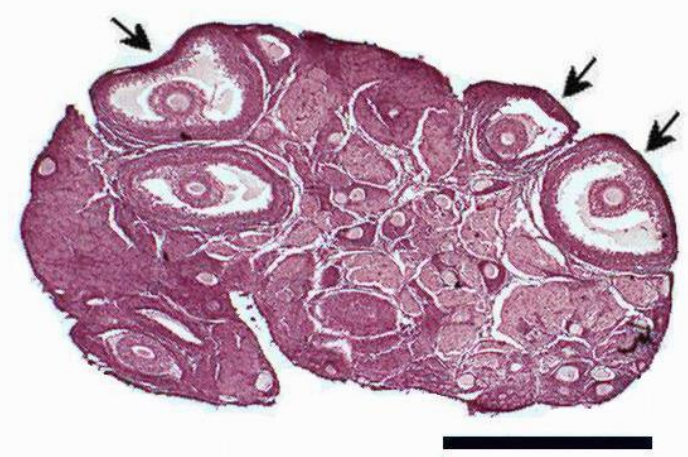

A

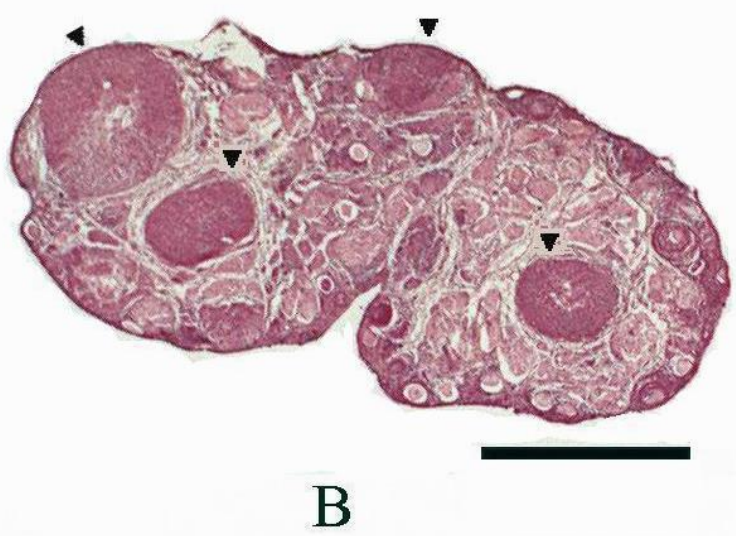

Figure 1. Sections of ovaries from (A) a 33-day-old stoat female on day 2 pc and (B) a 53-day-old stoat female on day 9 pc. Arrows indicate preovulatory follicles, arrowheads indicate corpora lutea. (Haematoxylin and eosin stain; Scale bar $=1 \mathrm{~mm}$ ).

Oviductal flushings of female stoats $72-96 \mathrm{~h}$ pc yielded oocytes as well as live spermatozoa. In one donor female ovulation occurred three days ( $72 \mathrm{~h} \mathrm{pc}$ ) after mating; in another donor female, it happened one day later, $96 \mathrm{~h} \mathrm{pc}$ (Table 1). Ovulated eggs flushed from the oviducts on days 3 and 4 were characterized by a dark ooplasm encompassed by zona pellucida. These ovulated eggs at the time of collecting were already free of follicle cells, and showed the first polar body which had been already extruded into the perivitelline space (Figure 2B).

Cleavage stage embryos were recovered from the oviducts on day $7 \mathrm{pc}$ (Figure 2C, Table 1).

Morulae were first seen in oviductal flushings on day 9 pc (Figure 2D). It seems that in the stoat, the beginning of cavitation and embryo migration from the oviducts into the uterus occur on day $11 \mathrm{pc}$, as on this day the flushing yielded both morulae (Figure 2D) and early blastocysts (Figure 2E), and the embryos were distributed between oviducts and uterine horns (Table 1). However, day-12 embryos were flushed exclusively from the uterine horns, but not from the oviducts, and were at the stage of early blastocyst. Our results indicate that stoat preimplantation embryos feature a prolonged period of oviductal residence. Corpora lutea $(\mathrm{CL})$ were observed in ovaries during oviductal journey of stoat embryos, although these $\mathrm{CL}$ were of relatively small size (Figure $1 \mathrm{~B}$ ). 
Table 1. Embryo recovery results in the 13 female stoats during nine months of pregnancy ( $\mathrm{n}=25$ uterine horns and oviducts, one uterine horn and oviduct was not investigated)

\begin{tabular}{|c|c|c|c|c|c|}
\hline $\begin{array}{l}\text { Days post } \\
\text { coitum }\end{array}$ & $\begin{array}{l}\text { Live spermatozoa in } \\
\text { reproductive ducts }\end{array}$ & $\begin{array}{l}\mathrm{PF} \text { or } \mathrm{CL} \text { in } \\
\text { ovaries }\end{array}$ & $\begin{array}{l}\text { Embryos/eggs in } \\
\text { reproductive ducts }\end{array}$ & $\begin{array}{l}\text { No. of recovered } \\
\text { eggs/embryos }\end{array}$ & $\begin{array}{l}\text { No. of horns/ } \\
\text { oviducts }\end{array}$ \\
\hline 4 & uterus, oviduct & $\mathrm{PF}^{\mathrm{c}}, \mathrm{CL}^{\mathrm{b}}$ & $\begin{array}{l}\text { Absent }{ }^{a} \text {, oviduct: } \\
\text { oocytes }^{b}\end{array}$ & $11^{\mathrm{b}}$ & 7 \\
\hline 7,9 & not detected & $\mathrm{CL}$ & oviduct: Cleav, M & 15 & 3 \\
\hline 11 & not detected & $\mathrm{CL}$ & $\begin{array}{l}\text { oviduct and } \\
\text { uterus: } \mathrm{M}, \mathrm{EB}\end{array}$ & 3 & 1 \\
\hline 12 & not detected & $\mathrm{CL}$ & uterus: EB & 5 & 1 \\
\hline $21-251$ & not detected & $\mathrm{CL}$ & uterus: DB & 66 & 12 \\
\hline 272 & not studied & not studied & uterus: IMP & IMP & 1 \\
\hline Total & & & & 100 & 25 \\
\hline
\end{tabular}

$\mathrm{PF}$, preovulatory follicles; $\mathrm{CL}$, corpora lutea,; Cleav, cleavage stages; $\mathrm{M}$, morulas; $\mathrm{EB}$, early blastocyst; $\mathrm{DB}$, diapausing blastocyst; IMP, implantation

${ }^{a}$ Four females were studied days 1-4 pc (one female each day). Ovulation happened only on day 3 pc (one female) and on day 4 (one female)

${ }^{\text {b}}$ Detected only in ovulating females

'Detected only in non-ovulating females

Embryos persisted in the uterine horns of the studied female stoats at the blastocyst stage since day 12 pc. until the following spring, i.e. 8-9 months (Table 1). Delayed stoat blastocysts contained a single layer of trophoblast cells surrounding a blastocoel. A disk consisting of round dark-coloured cells, i.e. the inner cell mass (ICM), protruded into the blastocoel cavity (Figure $2 \mathrm{~F}$ ). Although no signs of cell differentiation were noticed during the period of delayed implantation, the size of the embryos had increased and by the time of implantation the embryos were larger than at the beginning of delay (Figure 3).

According to our observations, all flushed embryos were encompassed with intact embryonic coats, no signs of hatching or dissolution of zona pellucida were observed. To study the timing of implantation two females were investigated at the beginning of April. The first female was examined on April 2nd, which was day 234 of its pregnancy. Only one uterine horn of this female was investigated, the other remained intact. The first black spots indicative of moulting appeared on the winter fur of this female five days after the operation and it whelped 27 days after the operation. One of the four embryos flushed from its removed horn (Figure 4A) was fixed and sectioned. A distinctly separated population of cells could be distinguished on the inner surface of the ICM (Figure 4B), indicating the beginning of gastrulation by the specialization of primary endoderm. Another female was investigated $270 \mathrm{dpc}$, on April 6th immediately after the appearance of the first black spots on the winter fur of this female. Flushing of the embryos was impossible, and implantation sites were recorded. 
A
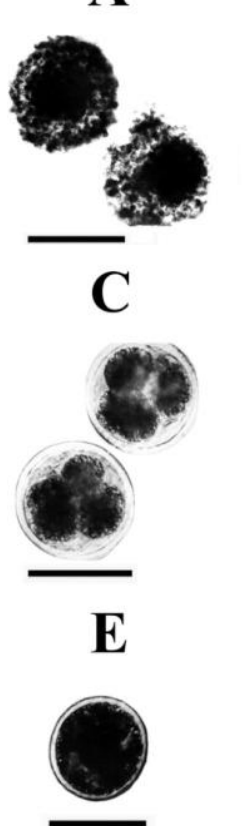

B

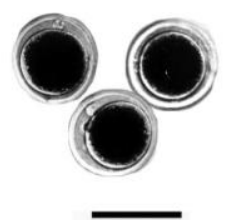

D

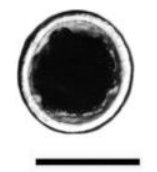

$\mathbf{F}$

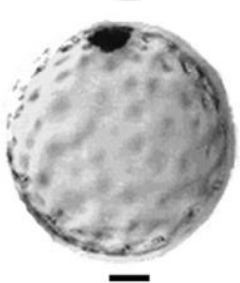

Figure 2. Preimplantation embryo development in the stoat from ovulation and during diapause (representative examples). A. Oocytes before ovulation extracted from preovulatory follicle on day 2 pc. B. Ovulated oocytes, oviducts, day 3 pc. C. Cleavage-stage embryos, oviducts, day 7 pc. D. Morula, oviduct, day 9 pc. E. Early blastocyst, uterine horn, day 12 pc. F. Diapausing expanded blastocyst, uterine horn, day 34 pc. Modified from [16], (unstained; light microscopy; scale bar $=100 \mu \mathrm{m}$ ).

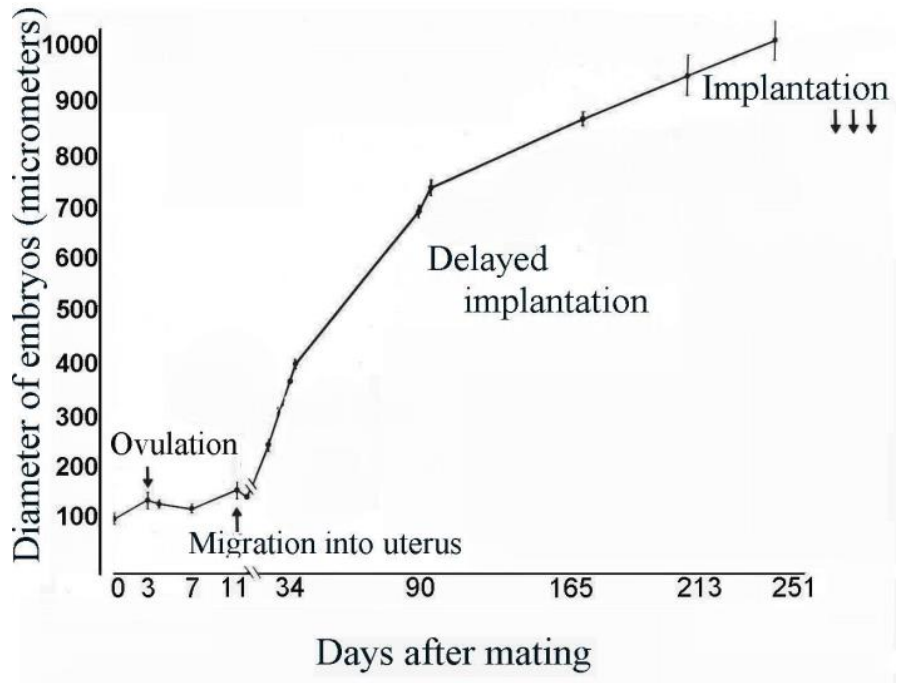

Figure 3. Embryonic growth in the stoat during the preimplantation period. Diameter of embryos at each day of pregnancy is represented as mean \pm SEM of the sample of embryos flushed on this day. More details on the numbers of embryos flushed during different periods of pregnancy are presented in Table 1. Modified from [19]. 

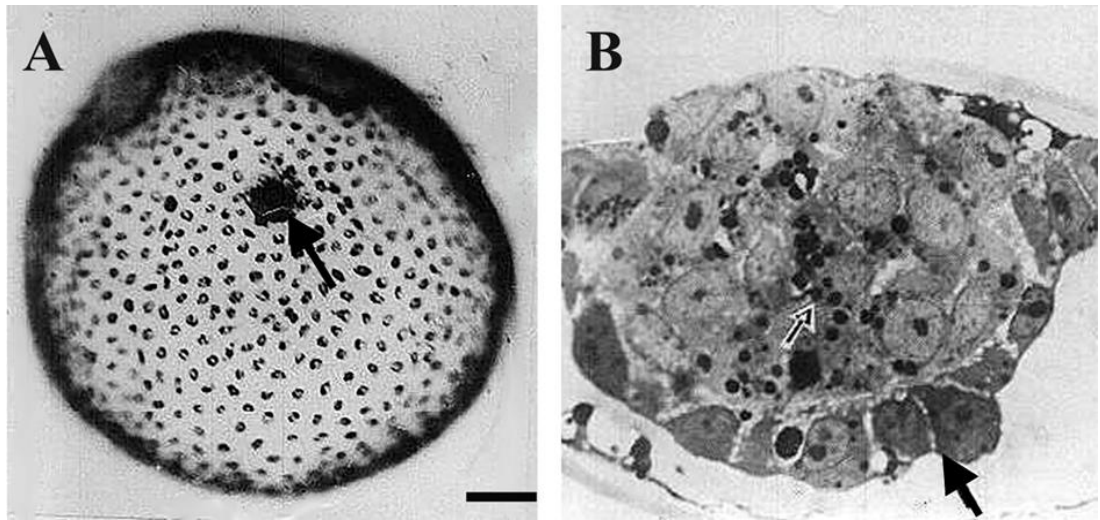

Figure 4. A. Expanded blastocyst at activation stage, a few days before implantation, uterine horn, $234 \mathrm{dpc}$. Arrow indicates ICM (unstained; light microscopy; scale bar $=100 \mu \mathrm{m}$ ). B. Section through the ICM of the same blastocyst; black arrow indicates the distinct layer of cells indicating the initial stage of endoderm differentiation. Small white arrow indicates large lipid droplets.

\section{Discussion}

In all the stoat females used as embryo donors in this study, oestrus had occurred during the first month of their life, at their neonatal period. In oestrous, stoat vaginal swelling was observed and cornified cells were the predominant cell type in the vaginal smears. The majority of the studied females came into oestrus on postnatal days 17-18 and were able to copulate with adult males, as evidenced by observation of coitus, and the presence of spermatozoa in the vaginal smears after mating. The phenomenon of precocious maturation in stoat females was discovered earlier on the captive bred population of stoats in Novosibirsk, maintained for many years by Dmitry and Julia Ternovsky $[10,15]$. Taken together, our data reported herein and observations made by Dmitry and Julia Ternovsky allow to conclude that, in the northern hemisphere, female stoats enter oestrus during the first month of their life, i.e. during May-June, and may stay in oestrus the whole summer until impregnated by an adult male. Our observations presented here and elsewhere $[16,19]$ provide experimental evidence of ovulation and embryonic development in such young stoat females fertilised by the adult males. Taken together, these observations suggest that the precocious sexual maturation of stoat females during weaning period is characteristic for this species. Field studies of stoat females performed in New Zealand are in a good agreement with our conclusions [21]. The long-tailed weasel (Mustela frenata) is characterised by the similar reproductive phenomenon [22]. To the best of our knowledge, only the stoat and the long-tailed weasel possess precocious sexual maturation as an obligate feature for female reproductive development.

Mustelids are known to be induced ovulators [20,23]. According to observations reported herein, the interval between copulation and ovulation in stoat is as long as 72-96 hours. In the ferret, the mustelid with comprehensively studied reproductive biology, the interval between copulation and ovulation is also relatively long: 30-40 hours [23]. The relatively long period between copulation and ovulation seems to be associated in mustelids with a prolonged period of sperm survival in the female's reproductive tract. Chang (1965) demonstrated that the ferret spermatozoa retained their fertilising capacity in the female reproductive tract for 126 hours [24]. These observations on prolonged time of sperm survival in ferrets are in a good agreement with our observations on the stoat presented herein and elsewhere $[16,19]$. In the common farm animals like cattle, pigs and sheep, the fertile life of spermatozoa in female reproductive ducts is shorter and does not exceed two days, i.e. 48 hours [25]. The relatively long time of sperm survival observed in our studies with stoats and in the cited studies with ferrets may be considered as a specific reproductive characteristic of the Mustelidae family associated with the induced ovulation. 
In the ferret, a non-diapausing mustelid species, oviductal journey of embryos encompassed period of seven days $[23,26]$. In another non-diapausing mustelid, the European mink (Mustela lutreola), embryos enter the uterus from day-6 pc [27] onwards. In these non-diapausing mustelid species as well as in their diapausing Mustelidae/Mephitidae relatives studied so far, e.g. American mink (Neovison vison) and western spotted skunk (Spilogale gracilis); blastocysts develop at a period approximately a week after mating [26-28]. Thus, a prolonged period of oviductal residence in the stoat and slow rate of cleavage is a specific characteristic of the stoat. It should be noted, that the stoat is perhaps "the slowest" in its early embryonic development among the studied mustelids.

In the studied stoat females, we observed no visible changes in the CLs during the first weeks after mating. It has been shown, that progesterone levels in the diapausing stoat females remain low during most of the pregnancy and there are no differences in plasma progesterone concentrations between pregnant and unmated stoat females for several months until the time of blastocyst activation and implantation [29]. Thus, the reason for the slowing down of stoat embryo development, and for remaining embryos in a state of dormancy for several months, may be nonfunctional CLs during the period of diapause. Currently more than 20 species of Mustelidae family are recognised as demonstrating diapause [2]. In a number of Mustelidae species, this embryonic diapause lasts for several months, as in the western spotted skunk or badger (Meles meles) [30,31]. In contrast to species of other zoological taxa, diapausing blastocysts in mustelids being still encapsulated by embryonic coats that increase in size with time as indicated by our observations on the stoat presented herein and elsewhere $[16,19]$ as well as by reports on the western spotted skunk [30] and badger [31]. The gradual increase in the diameter of the diapausing blastocyst in Mustelidae is due to fluid accumulation within the blastocoel and accompanied by the increase in cell numbers in the trophoblast, as has been confirmed for the western spotted skunk [30].

At the beginning of April the first signs of differentiating were observed in the stoat blastocyst coinciding with the first signs of moulting. The beginning of the differentiating process in the ICM was considered as the marker of the activation in another diapausing species, the spotted skunk and indicated the very beginning of gastrulation [30]. The first black spots on the fur mark the start of moulting and are indirect indicators of implantation in stoats (Dmitry Ternovsky, personal communication). Our data confirm the view that the increasing photoperiod is the proximal stimulus for the escape of the embryos from diapause in mustelids [32].

Our results presented here and elsewhere $[16,19,20]$ indicate, that the stoat possesses an unusual combination of reproductive features: obligate embryonic diapause which lasts up to nine months, precocious sexual maturation of females, which may be successfully impregnated by the adult males during the first month of their life, induced ovulation, unusually long time (up to four days) of spermatozoa survival in the female's reproductive ducts and the long period of oviductal residence of developing embryos. This constellation of these reproductive features make this small mustelid species a valuable model for reproductive studies.

\section{Declaration of interest}

The authors declare that there is no conflict of interest that could be perceived as prejudicing the impartiality of this article.

\section{Funding}

This study was supported by budgeted project 0324-2019-0041-C-01 for the Institute of Cytology and Genetics (Russia), and by the Russian Foundation for Basic Research, project 19-016-00025. 


\section{Acknowledgements}

The authors are grateful to Dmitry and Julia Ternovsky whose basic research on the stoat was a ground to initiate this work and to Eduard Chuyko for his help with preparing illustrations for this article.

\section{References}

[1] Fenelon JC, Lefevre PL, Banerjee A \& Murphy BD. 2017 Regulation of diapause in carnivores. Reprod Domest Anim 52 12-17

[2] Deng L, Li C, Chen L, Liu Y, Hou R \& Zhou X. 2018 Research advances on embryonic diapause in mammals. Anim Reprod Sci 198 1-10

[3] Lefevre PLC, Palin M-F, Beaudry D, Dobias-Goff M, Desmarais J, Llerena EM \& Murphy BD. 2011 Uterine signaling at the emergence of the embryo from obligate diapause. Am J Physiol Endocrinol Metab 300 E800-808

[4] Fenelon JC \& Murphy BD. 2017 Inhibition of polyamine synthesis causes entry of the mouse blastocyst into embryonic diapause. Biol Reprod 97 119-132

[5] Cha J, Sun X, Bartos A, Fenelon J, Lefevre P, Daikoku T, Shaw G, Maxson R, Murphy BD, Renfree MB \& Dey SK. 2013 A new role for muscle segment homeobox genes in mammalian embryonic diapause. Open Biol 3 E130035

[6] Fu Z, Wang B, Wang S, Wu W, Wang Q, Chen Y, Kong S, Lu J, Tang Z, Ran H, Tu Z \& He B. 2014 Integral proteomic analysis of blastocysts reveals key molecular machinery governing embryonic diapause and reactivation for implantation in mice. Biol Reprod 90 1-11

[7] Fenelon JC, Banerjee A, Lefevre P, Gratin F \& Murphy BD. 2016 Polyamine-mediated effects of prolactin dictate emergence from mink obligate embryonic diapause. Biol Reprod 95 1-13

[8] Cha J, Burnum-Johnson KE, Bartos A, Li Y, Baker ES, Tilton SC, Webb-Robertson B-JM, Piehowski PD, Monroe ME, Jegga AG, Murata S \& Hirota Y. 2015 Muscle segment homeobox genes direct embryonic diapause by limiting inflamation in the uterus. J Bioll Chem 290 15337-15349

[9] Renfree MB \& Fenelon JC. 2017 The enigma of embryonic diapause. Development 144 3199-3210

[10] Ternovsky DV \& Ternovskaya YuG. 1994 Ecology of Mustelidae. Nauka: Scientific Siberian Press. Novosibirsk (In Russian)

[11] Thom M, Johnson DDP \& Macdonald DW. 2004 The evolution and maintenance of delayed implantation in the Mustelidae (Mammalia: Carnivora). Evolution 58 175-183

[12] Ferguson SH, Higdon JW \& Lariviere S. 2006 Does seasonality explain the evolution and maintenance of delayed implantation in the family Mustelidae (Mammalia: Carnivora). Oikos 114 249-25

[13] Zhang H, Li D, Wang C \& Hull V. 2009 Delayed implantation in giant pandas: the first comprehensive empirical evidence. Reproduction 138 979-986

[14] Wright PL. 1963 Variations in reproductive cycles in North American mustelids. In: Enders AC (ed). Delayed Implantation. (University of Chicago Press: Chicago)

[15] Ternovsky DV. 1983 Biology of reproduction and development of ermine (Carnivora, Mustelidae). Rus Zool J 62 1097-1105

[16] Amstislavsky SYa, Maksimovsky LF, Ternovskaya YuG \& Ternovsky DV. 1994 Features of the biology of reproduction and development of embryos in the stoat. Rus J Zool 73 124-131

[17] King CM, Griffiths K \& Murphy EC. 2001 Advances in New Zealand mammalogy 1990-2000: stoat and weasel. J Royal Soc NZ 31 165-183

[18] Amstislavsky S, Lindeberg H, Aalto J \& Kennedy MW. 2008 Conservation of the European mink (Mustela lutreola): focus on reproduction and reproductive technologies. Reprod Domest Anim 43 502-513

[19] Amstislavsky S, Maksimovsky L, Ternovskaya Yu \& Ternovsky D. 1993 Ermine reproduction and embryo development. Scientifur 17 293-298

[20] Amstislavsky S \& Ternovskaya Yu. 2000 Reproduction in mustelids. Animal Reprod Sci 60 571-581 
[21] King CM \& Moody JE. 1982 The biology of the stoat (Mustela erminea) in the national parks of New Zealand. Part 4. Reproduction. NZ J Zool 9 103-118

[22] Wright PL. 1942 Delayed implantation in the long-tailed weasel (Mustela frenata), the short-tailed weasel (Mustela cicognani), and the marten (Martes Americana). Anatom Rec 83 341-353

[23] Lindeberg H. 2008 Reproduction of the female ferret (Mustela putorius furo). Reprod Domest Anim 43 150-156

[24] Chang MC. 1965 Fertilizing life of ferret sperm in the female tract. J Exp Zool 158 87-100

[25] Johnson MH \& Everitt BJ. 2000 Essential Reproduction, 5th ed. (Blackwell Science Ltd: London)

[26] Lindeberg H, Amstislavsky S, Jarvinen M, Aalto J \& Valtonen M. 2002 Surgical transfer of in vivo produced farmed European polecat (Mustela putorius) embryos. Theriogenology 57 2167-2177

[27] Amstislavsky S, Kizilova E, Ternovskaya Y, Zudova G, Lindeberg H, Aalto J \& Valtonen M. 2006 Embryo development and embryo transfer in the European mink (Mustela lutreola), an endangered mustelid species. Reprod Fertil Dev 18 459-567

[28] Fenelon JC, Banerjee A \& Murphy BD. 2014 Embryonic diapause: development on hold. Int J Dev Biol 58 163-174

[29] Gulamhusein AP \& Thawley AR 1974 Plasma progesterone levels in the stoat. J Reprod Fertil 36 405408

[30] Enders AC, Schlafke S, Hubbard NE \& Mead RA. 1986 Morphological changes in the blastocyst of the western spotted skunk during activation from delayed implantation. Biol Reprod 34 423-437

[31] Corner LA, Stuart LJ, Kelly DJ \& Marples NM. 2015 Reproductive Biology Including Evidence for Superfetation in the European Badger Meles meles (Carnivora: Mustelidae). PLoS One 10 E0138093

[32] Murphy BD. 2012 Embryonic diapause: advances in understanding the enigma of seasonal delayed implantation. Reprod Domest Anim 47 121-124 